\title{
Alexander Gordon (1752-99) and his writing: insights into medical thinking in the late eighteenth century
}

\author{
PN Bennett \\ Physician and Clinical Pharmacologist (retired)
}

\begin{abstract}
Alexander Gordon's writing reveals nascent ideas about infectious disease, tensions in medical thinking in the time of the Enlightenment, but also a practice of medicinal therapy that resonates with that of the present day. His Treatise on the Epidemic Puerperal Fever contained observations and deductions which provided, for the first time, compelling evidence of the contagious mode of transmission of the infection by medical attendants. He wrote the manuscript of The Practice of Physick sometime between 1786, when he began his practice in Aberdeen and 1795, the year of his abrupt departure from the city. The nearcomplete manuscript remained in the possession of his family (and therefore unavailable to scholars) until 1913 when a descendant gifted it to the library of King's College at the University of Aberdeen where it appears to have remained largely undisturbed.
\end{abstract}

KEYWORDS Alexander Gordon, physician, epidemic puerperal fever, The Practice of Physick

DECLARATIONS OF INTERESTS Dr Bennett has a contract with AuthorHouse to publish his transcription of Alexander Gordon's The Practice of Physick
Correspondence to PN Bennett, Denmede, Southstoke Road, Bath BA2 5SL, UK

tel. $+44(0) / 22583237$ I

e-mail mpspnb@bath.ac.uk

\section{ALEXANDER GORDON'S EARLY YEARS}

The son of a tenant farmer, Gordon was born in the hamlet of Milton of Drum, eight miles west of Aberdeen. An extract from the Old Parish Register of Peterculter in Aberdeenshire dated 20 May 1752 reads: 'Alexander Gordon in Milton of Drum had twins Alex and James baptised.' Their mother does not rate a mention. James grew up to contribute to the development of farming by propagating and perfecting the mode of cultivation of the Swedish turnip (the swede), becoming part of the agricultural revolution that greatly improved the nutrition and health of the Scottish people at the time. He died in I84I, in his ninetieth year, while his twin Alexander, the subject of this account, lived for only 47 years.

It seems unlikely that the family was financially well off but young Alexander Gordon succeeded in attending Marischal College in Aberdeen where, between I77I and 1775, he completed an arts degree, which would have included instruction in mathematics and Latin. Intent on following a career in medicine, the account of Gordon's life by lan Porter' places him as a student at the medical faculty of the University of Leiden in the Netherlands in March 1776. He seems to have enjoyed life in Leiden, writing in The Practice of Physik: 'When one goes in to a country where they [fevers] are endemic, as Holland, living a little more freely, and drinking a glass more than usual, tho' not to Excess, I know to be a good Preservative'.?
Prior to Gordon's time in the Netherlands, Leiden University had grown in reputation to rival that of Padua, largely due to the influence of Herman Boerhaave (16681738). Decades after his death, the impact of Boerhaave's teachings can be seen in Gordon's thinking and attitudes. The Practice of Physik refers to him in 17 instances, both agreeing and disagreeing with the Dutch physician. Teaching at the University took the form of topics rather than through recounting the writings of the ancient personages. Students learned to exhibit a caring attitude at the bedside and to take meticulous notes. After his time in Leiden, there is evidence that Gordon attended physicians' ward rounds at Aberdeen Infirmary, although the city had no formally established medical school. His notes of lectures by Alexander Monro secundus in the library of the University of Aberdeen ${ }^{3}$ indicate that he studied for a time in Edinburgh. They are undated but the matriculation roll of the Edinburgh Medical School records that an Alexander Gordon attended in 1779-80, making it likely that our subject was a student in that year.

After his time in Edinburgh Gordon joined the Royal Navy, serving as a surgeon's mate and ship's surgeon, a move that would have offered opportunity for adventure but also funding for further medical training before setting himself up in practice. In April 1785, he retired from the Navy on half-pay and spent nine months in London, as a resident pupil at the Middlesex and Store Street lyingin hospitals, where he heard lectures from leading 
obstetricians and attended dissections and lectures in surgery at the Westminster Hospital. Early in 1786, with an education gained in prestigious medical centres, he returned to practice in his native Aberdeen.

\section{PUERPERAL FEVER IN ABERDEEN}

Gordon became physician to the city Dispensary in February 1786, where he saw sick people as outpatients or in their own homes, an activity that continued throughout his time in Aberdeen. The keeping of accurate medical records was a hallmark of the Scottish medical Enlightenment. Gordon was required to maintain a log of the dates of each patient's attendance, their name, age, address, the presenting condition and its outcome; this discipline was to prove important for his later discovery about the spread of puerperal fever. Two streptococcal epidemics occurred in Aberdeen in the period 1789-92, erysipelas and puerperal fever. Both epidemics began, peaked and ended within the same timeframe. Gordon describes the concurrence in his Treatise (Figure I):

... almost every person admitted into the hospital of this place with a wound, was soon after his admission, seized with erysipelas in the vicinity of the wound. The same consequence followed the operations of surgery; and the cause was obvious, for the infectious matter which produces erysipelas was at the time readily absorbed by the lymphatics which were open to receive it. Just so with a respect to the puerperal fever; women escape it till after delivery, for, till that time there is no inlet open to receive the infectious matter which produces the disease. But after the delivery, the matter is readily and copiously admitted by the numerous patulous orifices, which are open to imbibe it, by the separation of the placenta from the uterus. And the same connection is evident from this circumstance, that a very frequent crisis of the disease [puerperal fever] is by an external erysipelas; which is proof that there is a metastasis or translation of the inflammation from the internal to the external parts. ${ }^{4}$

As physician-director of the Dispensary and the only local physician with recent training in obstetrics, Gordon was heavily involved with both epidemics. The Aberdeen puerperal fever was distinctive because it appeared not in the closed community of a lying-in hospital as was usual with this disease, but in the city and surrounding villages. This fever must be seen in the context of the medical beliefs of the time. The idea that disease could spread through a poisonous substance in the atmosphere had existed from the age of Hippocrates. Bad air or 'miasma', emanating from rotting organic material, waterlogged soil and decomposing animal remains was readily associated with rapidly advancing diseases, such as epidemics. In the seventeenth and eighteenth centuries, the notion of noxious substances in the environment was a popular

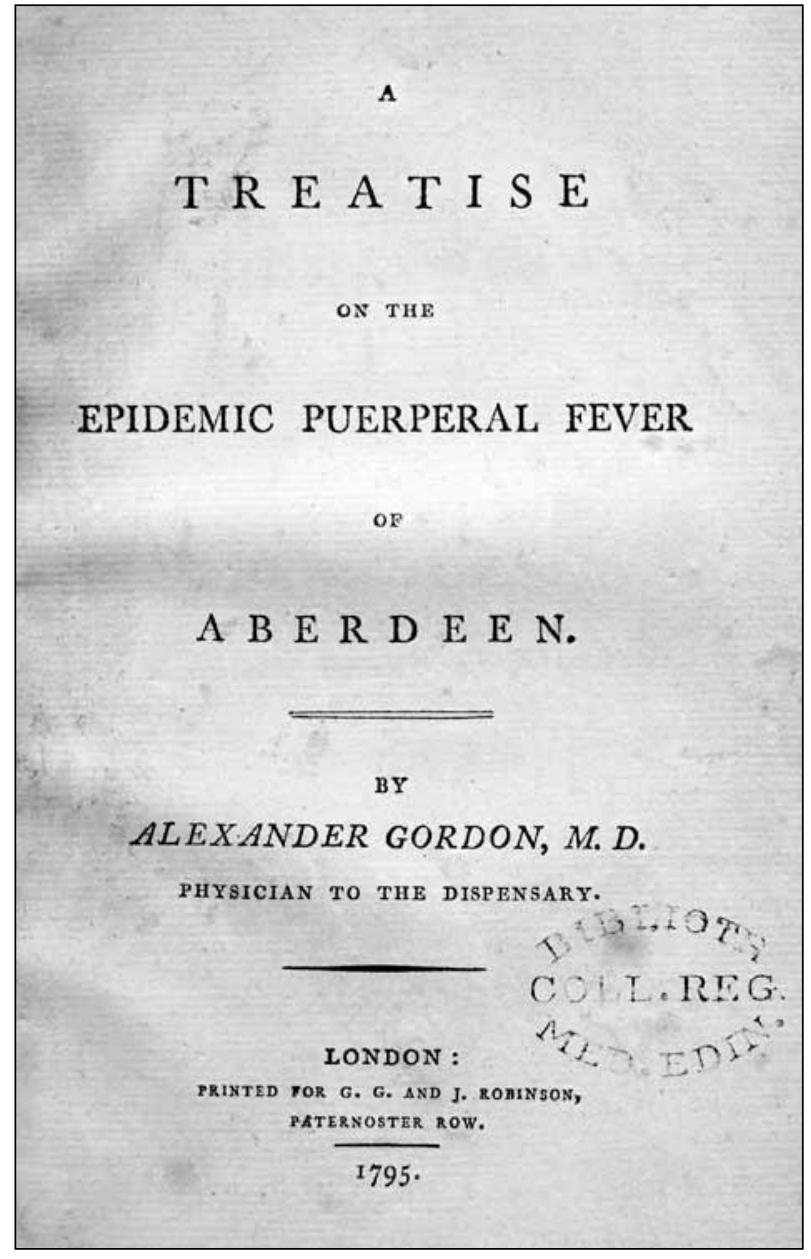

FIGURE I Frontispiece from A Treatise on the Epidemic Puerperal Fever of Aberdeen (The Royal College of Physicians of Edinburgh).

explanation for illnesses occurring in overcrowded and ill-ventilated places like jails, ships and workhouses, or indeed the foetid atmosphere of a lying-in hospital. This view, however, also had to accommodate the fact that some diseases did involve person-to-person transmission, as was manifest from the incidences of plague over many centuries and syphilis from the Middle Ages onwards. In reality, the division between miasma and contagion was not rigid and most accepted that disease aetiology was multifactorial. The advent and general acceptance of germ theory eventually resolved the debate in favour of contagion but the doctrine of miasmas made an important contribution; it probably promoted the nineteenth century developments in public health and sanitation.

Against this background, Gordon made two important discoveries. First, he noted that mothers living in the villages developed the fever if they were in the care of midwives from the city, where erysipelas was rife; village mothers attended by country midwives, who had no previous contact with the fever, avoided the disease. Secondly, in common with what was becoming part of 


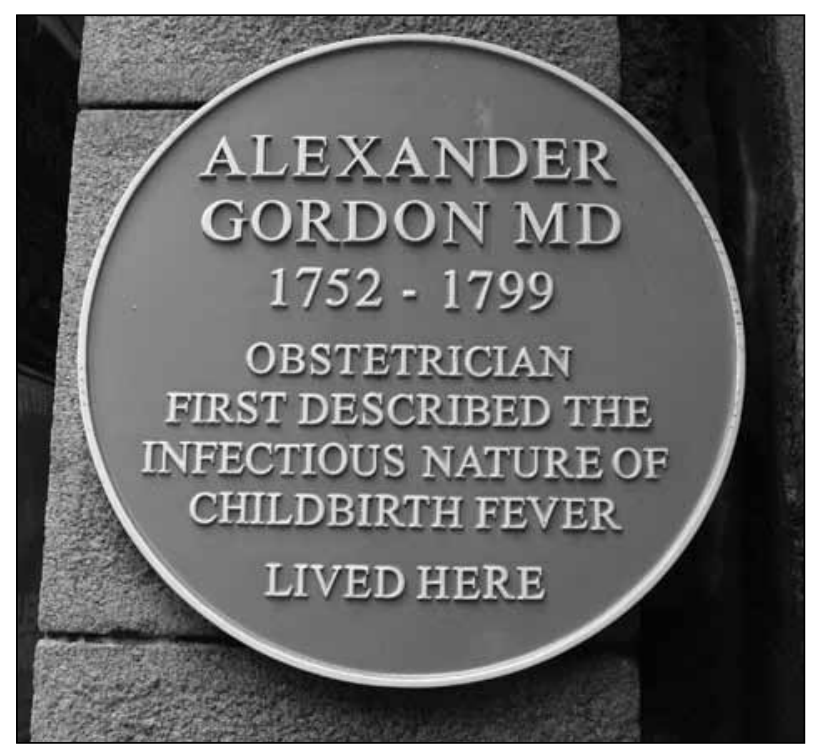

FIGURE 2 A plaque commemorating Alexander Gordon in Belmont Street,Aberdeen. (Image courtesy of Margaret Dundas.)

informed medical enquiry at this time, ${ }^{5}$ he created a table and noted the appearance of cases in date order, the maternal place of residence, the outcome and crucially, the name of the person who attended the birth. It was immediately apparent that cases of fever began in datesequence after visits by particular midwives. His Treatise records that:

The midwife, who delivered [case number] No 3, carried the infection to No 4; from No 24 to No 25, 26 and, successively, to every woman whom she delivered. The same thing is true of many others, too tedious to be enumerated. ${ }^{6}$

Furthermore, with impressive scientific objectivity, he implicates himself in the transmission, stating:

It is a disagreeable declaration for me to mention, that I myself was the means of carrying the infection to a great number of women. ${ }^{6}$

This evidence-based discovery long preceded the findings of Oliver Wendell Holmes ${ }^{7}$ in 1843 and Ignaz Semmelweiss ${ }^{8}$ in 1847, whose names are commonly associated with establishing the mode of transmission of puerperal fever.

Although not in the context of infection, Gordon refers in The Practice of Physik to Girolimo Fracastoro (1478I553) of Verona. In I546 Fracastoro intuitively conceived an accurate model of germ theory, which suggested that epidemic diseases were due to minute multiplying particles spread by direct contact, clothing and through the air. Gordon's thinking was similar, for he writes of 'fomites' and 'putrid particles' with the implication that they can transmit disease, stating that:
I had evident proofs that every person, who had been with the patient in the Puerperal Fever, became charged with an atmosphere of infection, which was communicated to every pregnant woman, who happened to come within its sphere. ${ }^{9}$

Gordon then counsels the physician who has seen a patient with severe fever to return home and change and fumigate his clothes.

By instituting hygiene measures that included hand washing, fumigation of rooms and burning of infected apparel, Gordon was able to claim 'In my practice, of 77 women, who were attacked with the Puerperal Fever, 28 died; so that very near two thirds of my patients recovered. ${ }^{10}$ He goes on to quote contemporary reports of puerperal fever mortalities in the range 68-100\%. Gordon appears to have been influenced by the success of James Lind (1716-94) in improving the health of sailors and that of John Pringle (1707-82) with soldiers through the implementation of sanitation procedures. The Practice of Physik makes repeated reference to these physicians.

Gordon named the patients and their medical attendants in his Treatise. Such disclosure was not uncommon at the time, but it would have presented him with a considerable dilemma. While he had a professional obligation to inform the public, and naming the participants lent veracity to his case, as he states in his Treatise: 'I saw the danger of disclosing the fatal secret.'

The outcome, inevitably, was extreme hostility towards Gordon, notably among the midwives whom he writes 'prompted by prejudice, very uncandidly, proclaimed the deaths, and concealed the cures, on purpose to raise an odium against my practice. This was hard...'." His recall to naval duties about this time may have been a welcome relief but two factors shed further light on his abrupt departure from Aberdeen and the apparent abandonment of his manuscript. First, about this time he donated a number of his books to the Medical Society of Aberdeen, including eight on obstetrics ${ }^{12}$ (his main specialist activity). Thus he may have sensed he was leaving his practice for an indefinite period, or even permanently. Second, the final page of the manuscript of his Practice of physick ends tantalisingly in midsentence. Gordon was under other pressures at this time, for he writes that the delay in publishing his Treatise '...was occasioned, partly by the laborious duties of my public office, but especially, by a complication of domestic calamities.' ${ }^{\prime 3}$ The latter may have included the death of his infant daughter. Given these combined personal and professional stresses, a plausible interpretation is that he simply stopped writing and left his home, and the manuscript of The Practice of Physik. 


\section{THE PRACTICE OF PHYSICK AND MEDICAL THINKING OF THE TIME}

Gordon's work originally comprised four volumes but the second volume is missing from the collection, possibly destroyed by fire, and the final volume is incomplete. It remained as a manuscript, although its original size (952 pages) and scope imply that he did intend to publish it. Nevertheless the remaining 683 pages, written by an intelligent, well-educated and widely read physician, provide a pertinent insight into professional medical practice in the late eighteenth century. Gordon's The Practice of Physik is now available in print. ${ }^{14}$

Gordon's manuscript reflects the tensions between changing ideas in medical thinking at the time. He makes repeated allusions to 'ancient' that is, humoral medicine, acknowledging phlegmatic, sanguineous, bilious and melancholic temperaments and constitutions. His vocabulary in respect of fluids contains humoral words such as 'acrimony' and 'concoction'. He provides detailed indications for the suitability of different forms of evacuation including emesis, catharsis, sweating, taking blood and cupping. He refers to the effects of climate, weather and the phases of the Moon on the course of illnesses.

It becomes clear however that what was influencing and directing Gordon's thinking most profoundly was a phenomenon that came to characterise Enlightenment medicine - evidence from recorded observations, his own and those of others. Indeed the author he quotes most frequently ( 26 times in the text) is the physician most closely associated with conclusions made from recorded clinical experience, Thomas Sydenham (1624-1689). Another feature of Enlightenment thinking, scepticism, is also prominent in his writing. Gordon's distrust of unsubstantiated theory is matched only by his belief in the value of personal experience:

In my opinion, a Rational Physician is a man, that can give the best reasons for his Practice, and I think the best reason is experience. ${ }^{15}$

At the time Gordon was writing his manuscript, Scotland was experiencing the creative and intellectual surge of the Enlightenment. Literati gave and attended lectures and met informally in each other's houses for discussion and the exchange of ideas across a range of disciplines including, in medicine, the application of reason to the well-being of mankind. ${ }^{16}$ Two notable figures of the medical Enlightenment, William Cullen (1710-90) and John Gregory (1724-73), seem to have exerted a particularly powerful influence on Gordon's thinking.

William Cullen was Professor of the Practice of Physic in Edinburgh and the most renowned medical teacher of his time. Building on the work of Albrecht von Haller (I708-

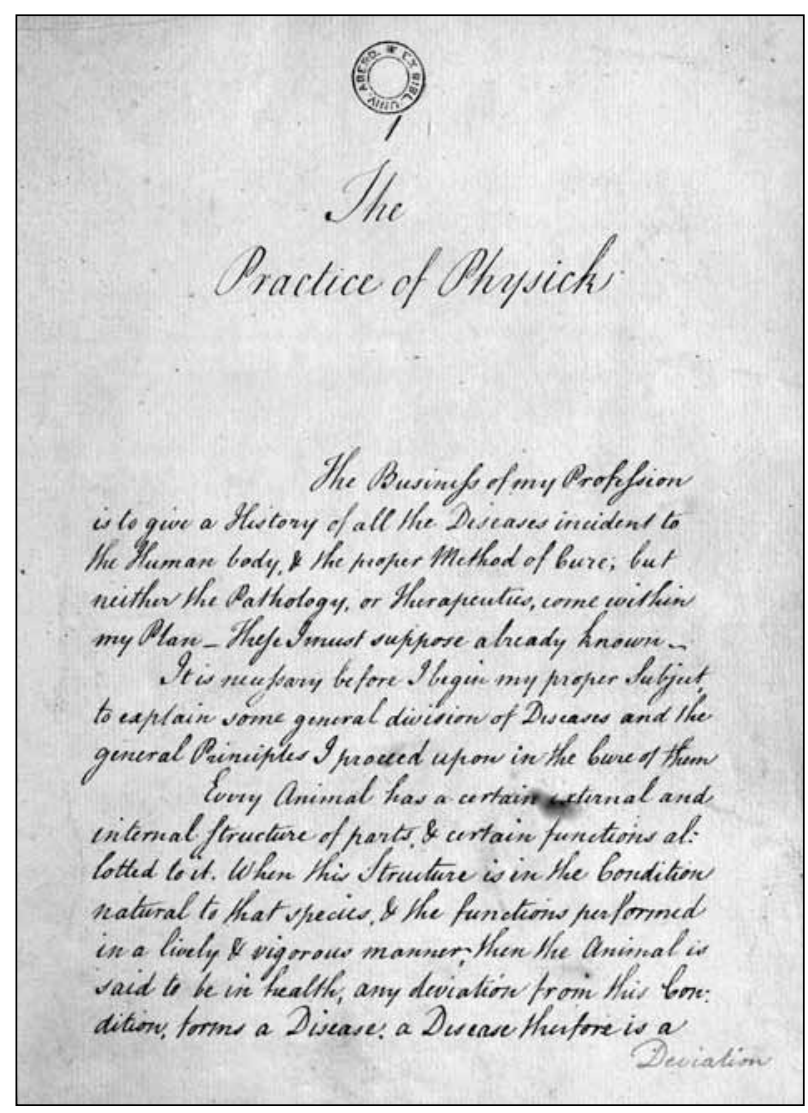

FIGURE 3 Page one of The Practice of Physick (reproduced with permission from the University of Aberdeen).

1777) on nerve and muscle function, he conceived the idea that life depended ultimately on nervous power; hence, that disease originated from disorder of the nervous system. ${ }^{17}$ More specifically, he proposed that the essential flow of fluids to organs depended on stimulation of the nerve supply to produce 'tonus' and disease followed lack of such stimulus. Gordon's text also makes frequent reference to the need for 'tonus', to 'lax habits', a 'lax system' and the need therefore to 'brace' the system.

At a time when there was no widely accepted concept of health, Gordon's writing was concerned with enquiry into the nature of illness and its source or 'seat'; he provided a list of causes with differing strengths of association to each of his accounts of disease: proximate, predisponent, occasional, exciting and antecedent. Where no convincing cause was apparent, Gordon referred to Cullen's teaching, writing that:

As therefore the Proximate Cause of fever, is neither in the solids or fluids, we naturally seek for it in the Nervous System. ${ }^{18}$

There was great interest at this time in nosology (the classification of disease) stimulated by the publication of the Systema naturae, a general taxonomy of nature written by the Swedish naturalist Carolus Linnaeus (1707-88). 
Cullen's nosology ${ }^{19}$ recognised just four classes of disease: pyrexiae (fevers), cachexias (diseases produced by bad body habits), neuroses (he was the first to use this word, meaning nervous diseases) and locales (local diseases). This classification, with subsidiary orders and genera, provoked widespread enquiry about the exact nature of disease. Gordon, for his part, offered a nosology with the following classes: febrile disorders, preternatural evacuations (e.g. haemorrhages), paralytic diseases, spasmodic diseases (e.g. epilepsy), diseases of the mind and cachexia (e.g. rickets, cancer); it had a more practical approach but the similarity to Cullen's ideas is evident.

John Gregory was Regent in Philosophy at King's College in Aberdeen, a post that carried professorial status, but he also practised medicine. He later settled in Edinburgh where he became Professor of the Practice of Physic with duties at the Royal Infirmary. His teaching and philosophy were influenced by Francis Bacon (I56I-1626) and like him, Gregory sought the establishment of a corpus of knowledge for interpreting nature by observation and experiment. In medical terms this is now known as evidence-based medicine, the evidence coming from an unbiased observation of the results of treating disease. Gregory was a friend of the philosopher David Hume and drew on Hume's principle of sympathy which has been defined as: 'The propensity to feel and think in tune with the feelings and opinions that we observe in others. This propensity is part of human nature. ${ }^{20}$ Sympathy was a 'core principle of Scottish Enlightenment moral sense philosophy ${ }^{21}$ and Gregory developed the idea that the physician should exhibit a humane and caring attitude towards the sick.

The practice of medicine at the time meant working in an unregulated marketplace. John Gregory's contribution was to combine Bacon's concept of knowledge from experience with the principle of a humane attitude to the sick thereby to form a coherent system. This called on practitioners of medicine to be scientifically and clinically competent, to place the interests of the sick before their own (reflecting the notion of sympathy) and to give priority to the needs of patients and the community over their collective or guild interests (which were dominant at the time). In effect, this system constituted the intellectual and moral requirements needed to turn medicine into a profession and provided the basis for the modern doctor-patient relationship. ${ }^{22}$

Gordon's own writing gave evidence both of the value of his belief in reason and experience and of a humane approach to the sick, for example by his scrutiny of medicinal therapy. He also exhibited an awareness of being part of a profession, for the very first words of The Practice of Physik are: 'The business of my Profession is to give a History of all the diseases incident to the Human body, and the proper Method of Cure.... ${ }^{23}$ Subsequently, he made a barbed comment about untrained practitioners: 'It is the Reproach of the Profession that so many have been cured by the rash Prescription of illiberate Quacks after being given over by the regular Physicians. These People however, have the advantage of Physicians that they have no character to lose. ${ }^{24}$

Gregory also unwittingly influenced the structure of Gordon's The Practice of Physik, for the subject headings of the latter follow those in Gregory's Elements of the practise of physic. ${ }^{25}$ Gregory's death curtailed the scope of his work but fortunately notes of his medical lectures taken by Thomas Gilchrist, possibly one of his pupils, still exist. ${ }^{26}$ These give subject headings that coincide with Gregory's published version and also show the subjects that he presumably would have covered had he completed his book. Gilchrist's subject headings indicate first, that the missing volume of Gordon's book would probably have included text on infectious disease, for example plague, phrenitis and ophthalmia and secondly, that Gordon's work was nearly complete for the final section of Gordon's manuscript describes 'diseases of women' which is also the concluding section of Gilchrist's notes.

\section{GORDON'S LATER CAREER}

Gordon spent the remainder of his working life in the service of the Navy. He practiced as a surgeon on the Adamant from January to April 1796 and then Overysse until August 1799. His entries in the medical journal of the latter ship provide some insight about him and his naval life. A poignant note about a seaman dated December 1797 reads: 'This poor fellow had neither shoes and stockings, and the weather being extremely cold, it was an act of humanity to send him to hospital. ${ }^{27}$ Another entry in March 1798 recalls his Aberdeen experience, as he describes an episode of fever in the ship's company following the introduction of a group of sailors from Sandwich '...which was speedily got the better of by sending the Patients affected to the Hospital as soon as the disease was distinctly marked... by observing the precaution mentioned it did not extend to the ship's company. ${ }^{28}$

In his book on Gordon, Porter notes that he appeared before the Court of Examiners of the Company of Surgeons in July 1796 with an unspecified illness or injury. The Court found that: 'Dr Alexander Gordon, not being wounded in Fight with the enemy, his Case does not come under the Cognizance of the Court'. ${ }^{29}$ It appears possible that, even in the first months of his service, he was exhibiting early signs of his final illness. The account of his grandson, Professor Alexander Harvey (I8I I-I889), Professor of Materia Medica at the University of Aberdeen from 1860 to 1878 , was that he had contracted a severe cold, which progressed to pulmonary tuberculosis. ${ }^{30}$ In the event, he was a sick man when he left the Navy on half 
pay in August 1799. He returned north to the home of his twin brother James who was farming at Logie in Aberdeenshire. Gordon died there on 19 October 1799; his remains lie in the family tomb adjacent to the west wall of St Nicolas Churchyard in Aberdeen.

\section{THINKING THEN AND NOW}

Despite an interval of two centuries, Gordon's analysis of the process of clinical decision-making evokes present day thinking. Some extracts from his writing on medicinal therapeutics illustrate this theme:

Where there is no clear Indication of diseases, what is proper to be done? If the disease is not very urgent, it is better for the Physician to lay by, rather than prescribe a Remedy, the Consequence of which he is not sure of. In point of Prudence however, he is often obliged to prescribe some Medicine, merely as a Placebo. ${ }^{24}$

In his view, the initial approach in some circumstances should be to question whether a drug is to be used at all. The place of a placebo, while out of tune with modern routine practice, might still have its advocates.

In all Chronic diseases, where the System seems to be affected, and the general Mass of fluids vitiated, those things which operate slowly, but have a constant effect upon the Constitution, are particularly to be attended to. These are the Circumstances of diet, Air, exercise, mineral waters, and an easy cheerful state of mind, all which in general come under the head of Regimen, and are often of more consequence, than any drugs whatever. ${ }^{31}$

Gordon's advocacy of healthy living to avoid the use of drugs accords with the objectives of modern health campaigns.

'Particular Regard ought always to be had to the state of the Patient's mind. The Spirits and vis vitae ought always to be supported as a much as possible in all diseases, particularly in all the nervous disorders, and stomachic, which always affects the mind more or less - Such affections I have often seen removed by agreeable conversation, and perhaps a bottle of Wine, especially in Hypochondriac Patients. ${ }^{31}$

Again, Gordon puts forward an alternative to the resort of prescribing medicines, especially for the nervous patient, at a time when the pace of medical practice perhaps permitted a more relaxed style of consultation.

Few medicines are to be prescribed, and these with the greatest simplicity. They ought not to be often changed, till a fair tryal is made of their Efficacy. By prescribing a Multitude of Remedies, and those too compounded, it is impossible to say to which the Cure is owing, and this is the Cause, why medicines lie so much in obscurity. A Physician I think should prescribe but one single medicine, unless he can give a reason for making an Addition such as to cover nauseousness, to make a Medicine sit easily on the Stomach, to prevent a Cathartic's griping etc. In such cases one or perhaps two Additions are necessarily. ${ }^{24}$

The advice to use as few medicines as will achieve the objective would readily find a place in any modern text on therapeutics, particularly in the case of elderly patients.

Lastly in those cases which appear to be desperate, and where the Patient by the course of the Disease is hastening to certain death, any Remedy, however desperate, that may have a chance of saving the Patient's Life, ought to be tried. But this must be managed with great delicacy, as very often the Physician's Character and subsistence depend upon the success of such Experiments and therefore I cannot recommend it as a general Rule. ${ }^{31}$

Gordon highlights a dilemma that is also familiar to modern physicians: in desperate situations, extreme remedies may be justified, but only after careful assessment of the balance between risk and benefit.

\section{CONCLUSION}

Gordon's analysis of data for A Treatise on the Epidemic Puerperal Fever of Aberdeen provided the first robust evidence of the contagious nature of this condition, although acceptance of his conclusions was long delayed. In a similar vein, The Practice of Physik delivered a graphic account of life as a physician (and as a patient) in the time of the Enlightenment, when many established beliefs were being challenged and changed. His thinking combined both acceptance of, and scepticism about, prevailing medical practice. The need for a sympathetic attitude towards the patient integrated with a recognition that decisions should be based on knowledge from personal experience and observation, formed the cornerstone of his practice. His scrutiny of the use of medicines is illustrative: despite an interval of over two centuries, his counsel emerges as rational and humane, and indeed resonates with that which underpins much of our present perspective on medicinal drug therapy. 


\section{REFERENCES}

I Porter IA. Alexander Gordon, M.D. of Aberdeen 1752-I799. Edinburgh: Oliver \& Boyd; 1958. p. II.

2 Gordon A. The practice of physick (transcribed with Glossary and Notes by P Bennett). Milton Keynes:AuthorHouse; 20 I I. p. 44.

3 Gordon A. Lectures on surgery. University of Aberdeen Library, Special Libraries \& Archives, MS 636.

4 Gordon A. A treatise on the epidemic puerperal fever of Aberdeen. London: GG and J Robinson; 1795. p. 57.

5 Tröhler U. The introduction of numerical methods to assess the effects of medical interventions during the 18th century: a brief history. J R Soc Med 20I I; 104:465-74. http://dx.doi.org//0.I258/ jrsm.20l I.I Ik025

6 Gordon A. A treatise on the epidemic puerperal fever of Aberdeen. London: GG and J Robinson; I 795. p. 64.

7 Holmes OW. The contagiousness of puerperal fever. $N$ England Quart J Med 1843; 1:503-30. Reprinted in: Medical Classics. Baltimore:Williams and Wilkie; 1936.

8 Semmelweis I. The etiology, concept and prophylaxis of childbed fever. Madison: University of Wisconsin Press; 1983.

9 Gordon A. A treatise on the epidemic puerperal fever of Aberdeen. London: GG and J Robinson; I795. p. 63.

10 Gordon A. A treatise on the epidemic puerperal fever of Aberdeen. London: GG and J Robinson; I795. p. 72-3.

II Gordon A. A treatise on the epidemic puerperal fever of Aberdeen. London: GG and J Robinson; I795. p. ix.

12 Porter IA. Alexander Gordon, M.D. of Aberdeen I 752- I 799. Edinburgh: Oliver \& Boyd; 1958. p. 38.

13 Gordon A. A treatise on the epidemic puerperal fever of Aberdeen. London: GG and J Robinson; I795. p.vii.

14 Gordon A. The practice of physick (transcribed with Glossary and Notes by P Bennett). Milton Keynes:AuthorHouse; 20II.Available from: http://www.authorhouse.co.uk/Bookstore/BookDetail. aspx?Bookld=SKU-000423297
15 Gordon A. A treatise on the epidemic puerperal fever of Aberdeen. London: GG and J Robinson; I795. p. 30.

16 Broadie A. The Scottish Enlightenment. Edinburgh: Birlinn; 2007.

17 Cullen W. First lines of the practice of physic. Edinburgh: William Creech; 1784.

18 Gordon A. The practice of physick (transcribed with Glossary and Notes by P Bennett). Milton Keynes:AuthorHouse; 201 I. p. 50.

19 Cullen W. Synopsis nosologiae methodicae. Edinburgh: A Creech and Murray; 1785

20 Mautner T. The penguin dictionary of philosophy. London: Penguin; 2000. p. 553.

2I McCullough LB. John Gregory's medical ethics and the reform of medical practice in eighteenth-century Edinburgh.J $R$ Coll Physicians Edinb 2006; 36:86-92.

22 Gregory J. Lectures on the duties and qualifications of a physician. London: W Strahan and T Cadell; 1772.

23 Gordon A. The practice of physick (transcribed with Glossary and Notes by P Bennett). Milton Keynes:AuthorHouse; 201 I. p. I.

24 Gordon A. The practice of physick (transcribed with Glossary and Notes by P Bennett). Milton Keynes:AuthorHouse; 20I I. p. 34.

25 Gregory J. Elements of the Practice of physic. 2nd ed. London: W Strachan and T Cadell.

26 Gregory J. Medical lectures. University of Aberdeen Library, Special Libraries \& Archives, MS 2784.

27 Admiralty Medical Records, HMS Overyssel, 8 December 1997 (Alexander Gordon Archive,Aberdeen Medico-Chirurgical Society).

28 Admiralty Medical Records, HMS Overyssel, 9 March 1798 (Alexander Gordon Archive,Aberdeen Medico-Chirurgical Society).

29 Porter IA. Alexander Gordon, M.D. of Aberdeen I 752-I 799. Edinburgh: Oliver \& Boyd; 1958. p. 52.

30 Porter IA. Alexander Gordon, M.D. of Aberdeen 1752-I 799. Edinburgh: Oliver \& Boyd; 1958. p. 53.

3I Gordon A. The practice of physick (Transcribed with Glossary and Notes by P Bennett). Milton Keynes:AuthorHouse; 20I I. p. 35.

\section{SENIOR FELLOWS' CLUB PRIZE}

The Senior Fellows' Club Prize for 20II has been won by Dr AD McCallum, for his paper entitled 'Non-tuberculous mycobacterial infections in the Scottish Borders: identification, management and treatment outcomes - a retrospective review'. This can be seen in our December 201 I issue at:

\section{http://www.rcpe.ac.uk/journal/issue/journal_4I_4/faccenda.pdf}

A prize of $£ 250$ will be awarded to the first-named (or corresponding) author of an original research paper on a clinical topic, deemed by a panel of judges to be the best paper by a doctor-in-training (i.e. pre-consultant level) published in the The Journal of the Royal College of Physicians of Edinburgh in 2012. The best paper will be selected by a panel of judges, including a senior Fellow, an active clinician and a member of the editorial team.

Further details may be obtained from the Editorial Office, RCPE, 9 Queen Street, Edinburgh, EH2 IJQ, tel 0|3I 2473652 or email editorial@rcpe.ac.uk. 